\title{
Advances in inflatable packer technology and application
}

\author{
CJ Rowe Inflatable Packers International Pty Ltd, Australia \\ FJ Ford Inflatable Packers International Pty Ltd, Australia
}

\begin{abstract}
Advances in inflatable packer technology have been made in response to the demands of increasingly severe application environments resulting from deeper and deeper underground mining activities, often in remote locations. These include the development of tools to enable deep high pressure permeability testing and hydraulic fracturing activities such as pre-conditioning for block caving, rockburst mitigation and stress testing. In some cases, oilfield type equipment has been adapted for deep underground drilling activities requiring high pressure waterflow control. All of this was implemented using an Australian developed inflatable packer technology. Future developments of this technology may play a role in shale oil and gas exploration and production as well as hard rock in situ leach mining.
\end{abstract}

Keywords: inflatable packers, hydrofracture, permeability, rockburst, pre-conditioning

\section{Introduction}

Inflatable packers and associated equipment are often used for hydrological investigation of mine sites and extensions. Typically these involve determination of in situ rock permeability and/or stress conditions. These tools are also used in some direct mining activities, such as pre-conditioning for caving, and indirect activities, such as rockburst mitigation.

Historically, the activities available when using inflatable packer systems were limited by the pressure ratings of the inflatable elements and the tools available for their use. With the more recent advent of progressively deeper underground mines, along with 'new' mining activities, the tools necessary to undertake associated higher pressure applications have forced the evolution of more robust systems that also offer more versatility in terms of tool functionality.

This paper reviews some of these developments within the contexts of:

- Permeability testing.

- Stress testing.

- Hydraulic fracturing for pre-conditioning and rockburst mitigation.

- Crossover oilfield technology.

\section{$2 \quad$ Permeability testing}

\subsection{Earlier systems}

The basic testing methodology for a permeability test is to isolate a section of a borehole using a packer or packers and to inject water into this isolated zone at constant pressures and measuring the flow rate accepted to determine the rock permeability. Prior to the availability of more sophisticated systems, permeability testing for mining applications was typically conducted using packers installed using either drill rods or via wireline. The drill pipe method is rarely used in mining where the hydrological investigation is typically conducted during a mineral exploration coring program to minimise overall costs. Such a program lends itself to the wireline packer testing method initially patented in 1982 (Sweeney 1982). This method allows replacement of the inner tube of a wireline coring system via an inflatable packer assembly (Giacomel 
\& Rowe 1992). Once these packers are inflated to isolate the borehole zone of interest, a simple permeability test, typically a Lugeon test (Lugeon 1933), may be conducted, by pumping water through the drill rods into this zone, once the rods have been sealed on the surface.

For both the drill rod deployed and, the more prevalent and convenient, wireline systems the packers were inflated with gas via a small diameter hose run from the surface. As testing depth increases the surface gas pressure must also, necessarily, increase to overcome the increasing static fluid level sufficiently to inflate the packers and provide a seal against the differential pressure applied during testing. This can be readily accommodated at relatively shallow depths, say less than $\mathbf{3 0 0}$ metres, but as mine investigations became deeper and deeper, towards 1,000 or even 2,000 metres, the gas pressure requirements became increasingly impractical and potentially hazardous.

\subsection{Hydraulic packer systems}

To overcome the limitations of gas inflated packers, water inflated (hydraulic) packer systems were introduced. The first standard type of these that was designed to work with mineral coring systems labelled by its manufacturer as Standard Wireline Packer System (SWiPS) is described in Geodrilling International's November 2007 magazine (Geodrilling International 2007). This system performs in a similar fashion to the earlier gas wireline packer systems except that packer inflation is effected by pumping through the drill rods after the assembly has been installed in place of the wireline coring inner barrel. Subsequent to packer inflation, the tool opens (two different mechanisms are now available for this) to enable testing of the zone isolated by the packer or packers (Swanson \& Titone 2013).

In addition to overcoming the high pressure gas problems associated with earlier tools, this new system also extends the range of hydrological tests that may be performed. Lugeon tests may be performed as previously but, owing to the absence of either wireline or inflation hose while testing, formation in-flow tests can also be conducted by the use of a pumping system (such as airlift of a submersible) installed inside the drill rods. Furthermore, since the inflatable packers provided with these tools offer higher differential pressure rating than was previously available, such tools may even be used for low pressure hydro-jacking and hydro-fracture testing operations.

This hydraulic system has enabled permeability testing to keep pace with trends in mining, being able to operate deeper and in more remote sites with its higher pressure and 'light logistical' characteristics in that high pressure nitrogen gas cylinders are not required onsite. The system has opened up a whole range of testing that was previously not possible, such as in the Canadian Arctic or in remote jungle sites in Central Africa and Southeast Asia. There has even been the case of a major iron ore mining company in the Pilbara region of Western Australia using the system solely because it avoided the need for high pressure gas onsite and the resultant Occupational Health, Safety and Environment (OHSE) administration requirements.

To further extend the functionality of SWiPS for deep hole testing, a new wireline deploy tool known as STX-60 (Figure 1) was later introduced by the same manufacturer. This tool is based on one that was originally developed for drill stem testing of deep coal seams for the coal bed methane industry. The tool and its operation is described in Geodrilling International's October 2015 magazine (Geodrilling International 2015) but is, in essence, a tool that enables sophisticated packer testing through a conventional HQ core string. Since this tool is multi-set without needing to be retrieved to the surface it is particularly well suited for straddle testing in completed boreholes.

Apart from the higher pressure ratings available with this tool, its major contribution to increased effectiveness of hydrological testing is due to the fact that it includes a valve that enables shutting in of the test zone downhole. This single feature enables a further suite of tests that were not previously available significantly extending the usefulness of testing programs conducted with this equipment (Adams \& Roberts 2012).

Naturally, both of these new tools make provision for downhole pressure measurement by means of electronic memory gauges. This greatly improves the accuracy of pressure measurements during testing, 
particularly, at greater depths where pressure losses, due to flow over long distances through drill pipe, must otherwise be accounted for.

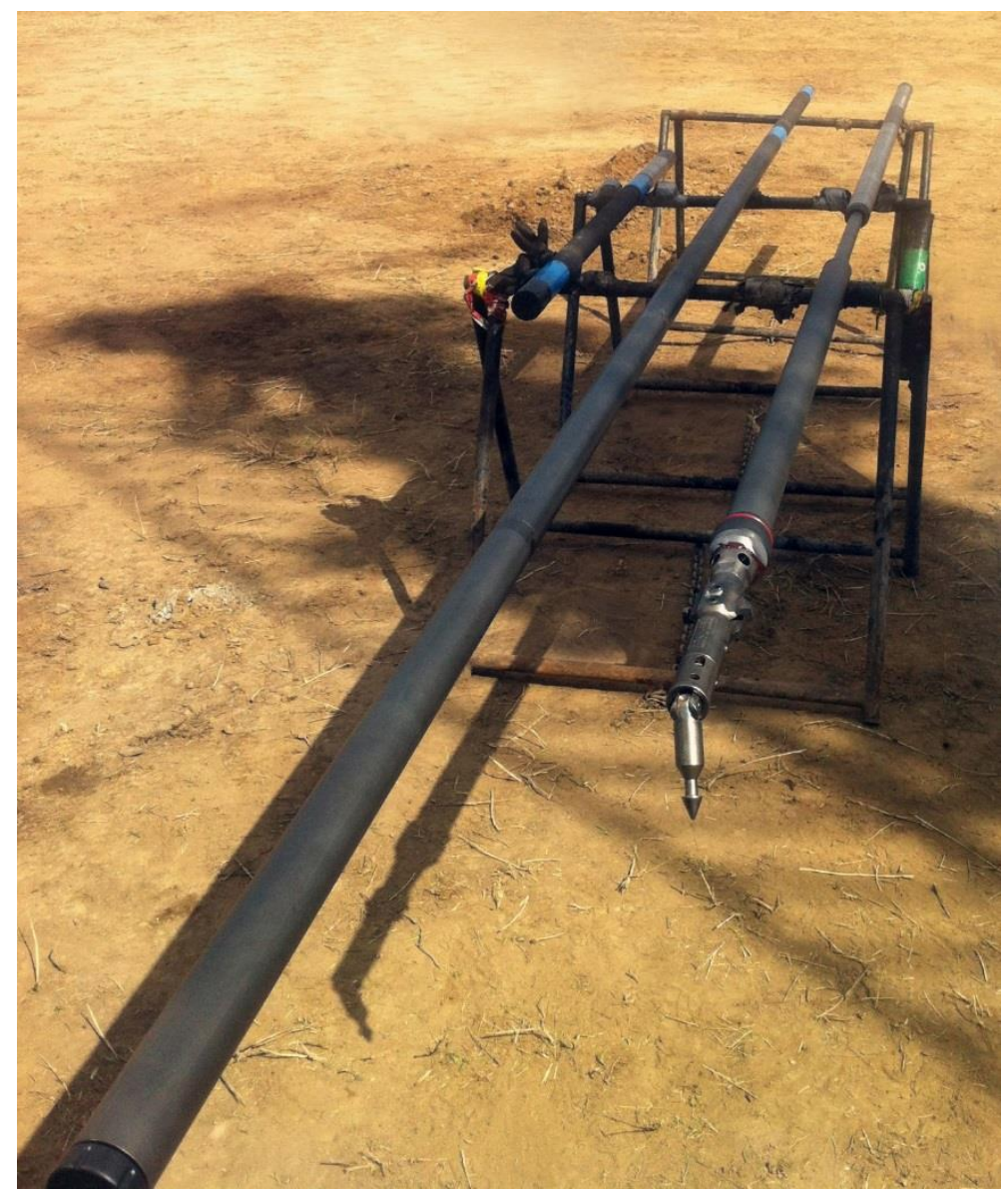

Figure 1 STX-60 on rig site in Queensland, Australia

\subsection{SWiPS versus STX-60 comparison}

Several test programs by various operators familiar with both the SWiPS and the STX-60 systems have concluded the following:

SWiPS

- Easy to use and can be understood very easily.

- Can be readily dismantled into small parts that can be easily handled and transported to and from site, thus, making logistics much easier, even in remote areas.

- The shear pin shears easily in deep holes so extra care should be taken when applying pressures to the element.

- The quality of data is good. This depends on how you handle the tool on the surface that directly influences the data collected on the surface using the flow meter and the downhole pressure transducer.

- Takes less time to service as it has less parts than the STX-60.

STX-60

- User friendly.

- Can be used on your way out of the hole when you miss important structures without delays and excessive standby time. 
- Can be readily dismantled into small parts that are easily handled and transported to and from site, thus, making logistics much easier, even in remote areas.

- Has the capability to do tests in deep holes without any problems including shut-in tests that are not available with SWiPS.

- Quality of data is excellent with minimum pressure spikes.

- The tool is very dynamic and reliable when stroking between the four different stages of operations, i.e. inflation/deflation, circulation, shut-in and injection/inflow tests.

- Provides the additional benefits of rapid deployment, ability to circulate fluids in troublesome wells during shut-in periods and easy and reliable packer inflation.

- The inflation and downhole activation system is superior in terms of efficiency and reliability and requires less maintenance when compared to the SWiPS tool.

- The time savings delivered through using the STX60 packer system when undertaking multiple short duration well tests in the same borehole was considerable and reduced drill rig utilisation time significantly.

- Significant safety improvements as a result of not having to remove the tool from the well for each new test interval that is required, dramatically reducing manual handling time and risks.

\section{$3 \quad$ Rock stress testing}

A frequently used technique for determining in situ rock stresses requires the use of hydraulic fracturing of the rock using inflatable packers for test zone isolation. This technique is sufficiently well established and accepted to warrant an American Society for Testing and Materials Standard (ASTM International 2008) and has received much further comment in authoritative journals, such as the International Journal of Rock Mechanics (Haimsona \& Cornet 2003).

Basically, it entails a section of borehole being isolated between two inflatable packers and the pressure between being raised by pumping fluid into it at a controlled rate until a fracture occurs in the borehole wall. Pumping is stopped and the pressure in the interval is allowed to stabilise. The pressure is then reduced to the pore pressure level of the rock formation, and the pressurisation/depressurisation process is repeated several times maintaining the same flow rate. The magnitudes of the principal rock stresses are calculated from the various pressure readings.

Until recently, owing to the pressure limitations of the inflatable packers employed, such testing was limited to a maximum rock breakdown pressure of around $40 \mathrm{MPa}(<6,000 \mathrm{psi})$. Through the application of Australian developed rubber reinforcement technology for inflatable packers and various tool design innovations, the pressure limits on the inflatable packers have now been raised to approximately $100 \mathrm{MPa}$ $(15,000 \mathrm{psi})$. This has significantly extended the applicability of this method of in situ rock stress measurement to deep and highly stressed environments.

Another relatively recent innovation in this area is the introduction of dual wall push rods for the installation of the inflatable packer systems into underground test bores. Push rods, in this context, are short lengths of pipe (or even solid bar) that attach to a straddle packer system and can be used to 'push' the system into the required depth in a borehole. Previously, these push rods were used only as a mechanical means of handling the packer assembly with packer inflation and test zone pressurisation being accomplished via separate, usually, stainless steel tubes.

An innovation originally introduced by Australia's CSIRO in their Minifrac System (which was subsequently commercialised by Mindata Pty Ltd), placed these separate tubes inside a pipe that provided the required mechanical strength and offered an integrated tool joint allowing simple coupling of one push rod to the next. This concept has now been simplified and taken to the next level by replacing the two tubes with one and using the inner diameter of this tube and the annulus between it and the outer mechanical tube as the 
fluid passages. This new design not only leads to a lighter rod (very important for manual installation) but is scalable both in terms of length and diameter to the extent that it is now being considered for other hydrofracturing operations such as those required for pre-conditioning for block caving.

These tools have been used by many investigators concerned with stress measurements and means of stress control for rockburst mitigation such as Makówka and Drzewiecki (2011) and Sengupta et al. (2013).

\section{$4 \quad$ Hydrofracture for preconditioning and rockburst mitigation}

Hydraulic fracturing as a rock preconditioning method for block cave mining was initially trialled in Northparkes Mines, Australia, porphyry copper-gold deposit in December 1997 (van As \& Jeffrey 2000). It has since proven to be a very cost-effective means of preconditioning for block caving. At the El Teniente mine, Chile (Figure 2), experience has demonstrated that seismicity and, thus, the risks of rockburst, can "be managed through preconditioning by the use of large scale hydraulic fracturing" (Pardo \& Rojas 2016).

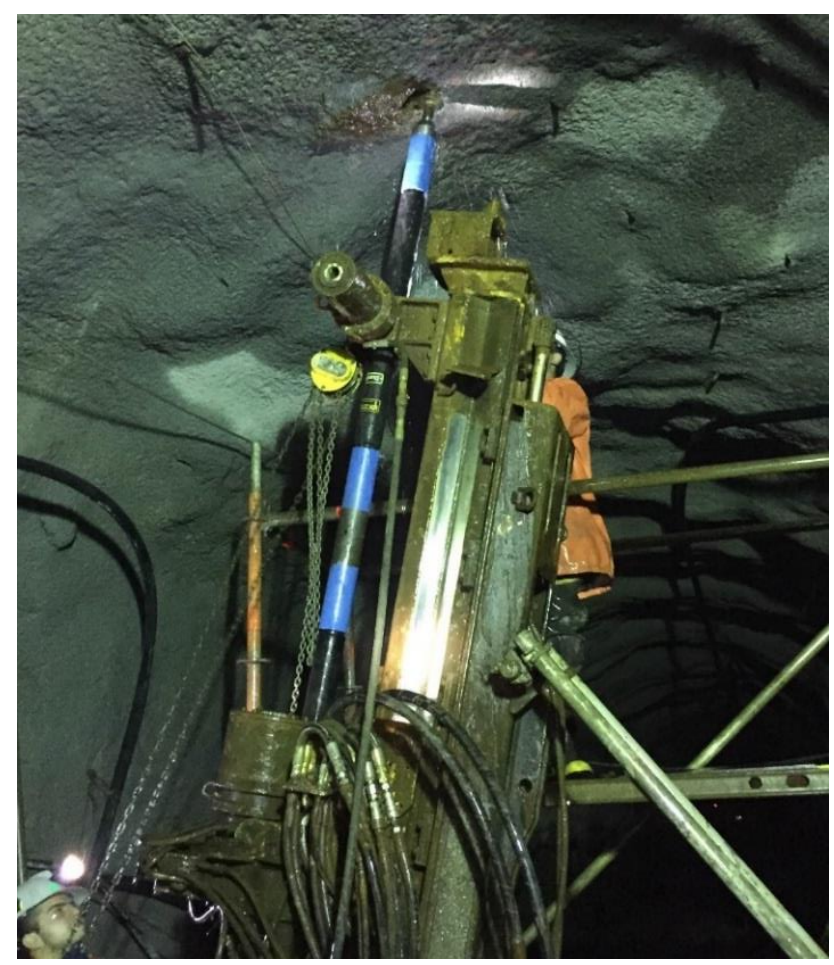

Figure 2 Hydrofracture for preconditioning using a straddle packer assembly

In brief, this method uses a straddle packer system installed in a pre-drilled borehole to isolate short treatment zones that are subsequently fractured using high pressure water. These new fractures intersect the borehole along its length, thus, providing artificial fractures in the rock to facilitate later caving. The ancillary benefit in this case is these new fractures reduce the in situ strength of the rock mass and, thus, can also be used to mitigate seismic hazard. In some applications, this latter effect is the primary reason for hydraulic fracture pre-conditioning rather than as an aid to caving.

Initial tooling used for these applications was adapted from existing rock stress hydro facture systems. This consisted of an $89 \mathrm{~mm}\left(3.5^{\prime \prime}\right)$ OD straddle packer assembly rated for $70 \mathrm{MPa}(10,000 \mathrm{psi})$ when used in HQ size cored holes ( $\left.96 \mathrm{~mm}-3.78^{\prime \prime}\right)$. This system was deployed on BQ drill rods with an external inflation hose.

These tools, with minor modifications, are still in use today, however, additional sizes, higher pressure ratings and other systems have since been introduced. The first of these was the $70 \mathrm{~mm}\left(2.76^{\prime \prime}\right)$ OD straddle packer system for use in NQ (76 mm - 3") boreholes, which also enabled a shorter straddle zone length to permit induced fractures to be placed more closely together. 
In part, as a response to deeper mining activities, pressure ratings have increased to $84 \mathrm{MPa}(12,000 \mathrm{psi})$ as standard with $105 \mathrm{MPa}(15,000 \mathrm{psi})$ systems being trialled. The basic tooling now also includes a pressure bypass system that minimises the build-up of pressure 'below' the straddle packer system to improve tool safety.

Possibly the biggest innovation with these tools has been the relatively recent introduction of models that do not require an inflation hose for operation of the packers. In these, a check valve arrangement is installed between the running pipe (still usually $B Q$ rod) and the packer system that allows the packers to inflate due to back-pressure generated across the check valve. Once the packers are sufficiently inflated the check valve opens and allows flow into the injection zone between the packers.

Other innovations that are anticipated in this sphere are the potential use of dual wall rods (as alluded to earlier in the push rods discussion) and the further increase in pressure ratings of the inflatable packers and other components.

The importance of pre-conditioning by hydraulic fracturing (HF), both to improve cave stability and to control seismicity, is reflected in its extensive use in the Codelco El Teniente Mine in Chile (Pardo \& Rojas 2016). As reported in this case, $\mathrm{HF}$ is performed in the major and the intermediate principal stress planes. Intensive HF is performed with borehole spacing reflecting the design assumption of the fractures extending 20 metres radially and with a spacing along the borehole axis of one fracture every 1.5 metres.

\section{Crossover oilfield technology}

Within the fields of drilling technology, there has always been a crossover of technology from the oilfield side to mining and vice versa. One new development in this area is the adoption by mining (and geotechnical) drillers of the blowout preventer (BOP), (see Figure 3) technology that has long been a necessary part of oilfield drilling operations.

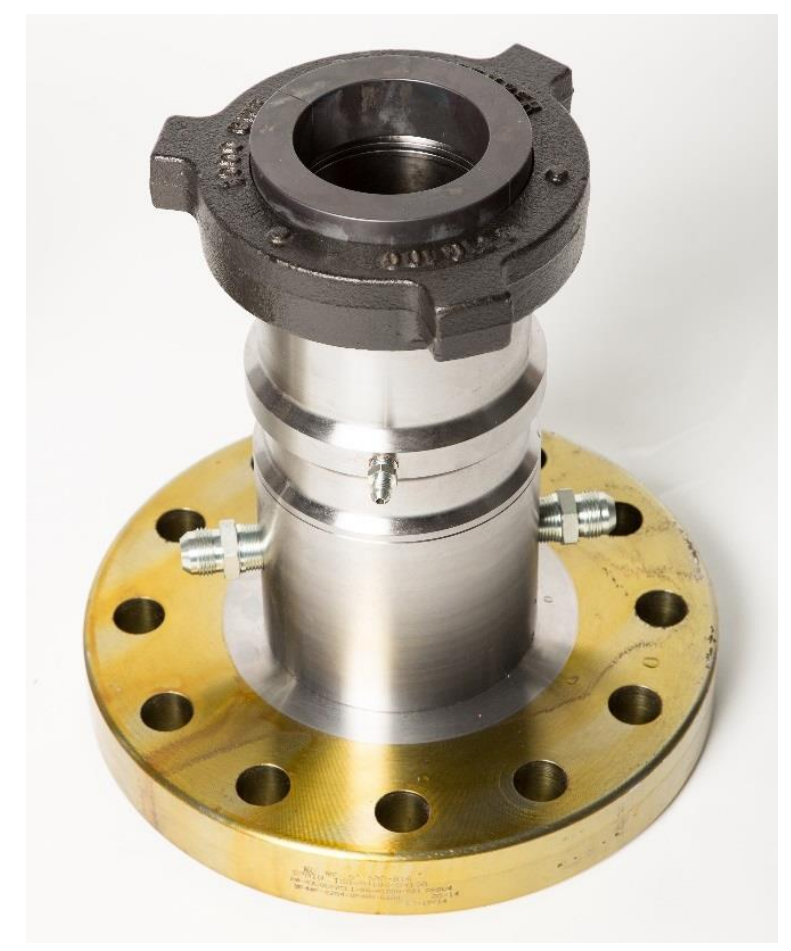

Figure 3 Low profile, mineral drilling blowout preventer

In simple terms, a BOP is a surface mounted sealing device that can seal the annulus between a surface casing and a drill pipe to prevent the uncontrolled release of well fluids from a borehole. With the increasing depth of mining drilling operations, particularly underground, and the attendant likelihood of intersecting high pressure sources of water, which may also have significant environmental impacts, the need for such devices has become apparent to this industry. 
Initially this need was met by the adoption of low pressure oilfield BOPs, such as those used in the coal bed methane exploration industry. However, particularly for underground operations, such devices are far too bulky, which has led to the development of more appropriately sized and rated BOPs.

One of these offers a mechanical sealing system that provides a running seal on the moving drill rods during most operations and an inwardly inflating packer that provides a very secure and complete seal when activated with the rods stationary. Below the annular seal is a hose connection that allows well fluids to be led away to a control tank or similar.

A further example of crossover technology is provided by the use of high temperature rated elastomers to cope with increasingly high temperatures encountered in some deep underground mining activities. For most civil engineering and mining applications the elastomer of choice is natural rubber (NR) owing to its low cost and great mix of properties at ambient temperatures. By contrast, in oil and gas applications the standard choice is nitrile rubber (NBR) which provides increased resistance both to hydrocarbons and to elevated temperatures. This latter property has been utilised to good effect to enable hydrological testing using inflatable packers in deep mining locations where the high temperatures due to volcanic activity exceeds the capability of NR.

\section{$6 \quad$ Future developments}

To begin looking at future developments we can consider another crossover technology which is expected though not yet implemented is that known as coiled tubing (CT) Systems. CT is simply based on using a small diameter continuous steel tube that is coiled onto a storage drum and fed into and out of a borehole by means of an injector head, which uses a set of continuous chains to feed the tubing.

This continuous roll of tube can take the place of drill rods for many applications. For example, when used with a downhole motor powered by mud pumped from the surface, it can be used for drilling operations. Being relatively flexible and being coupled with directional drilling techniques this system has been envisaged for use in many underground exploration and production drilling activities in the mining and geotechnical industries. Such applications are being explored by the Australian Deep Mining Technologies CRC, based in Adelaide.

It can similarly take the place of jointed pipe (drill rods) in other applications to run test and treatment tools into a borehole, for example, for hydraulic fracturing operations where the speed and efficiency of CT offers the possibility of automating pre-conditioning fracturing.

An area of considerable interest for deep mining operations is hard rock solution mining. In situ leaching, also known as in situ recovery or solution mining, is a method of recovering minerals that entails pumping of a leachate solution into the orebody via a borehole, which circulates via the porous or fractured rock dissolving the ore and is subsequently extracted by means of a second borehole. The ore laden leachate is then processed to recover the ore and separate the leachate for re-use.

This process has long been applied to uranium extraction but is now being studied for application to hard rock mining where the orebody is deep and not necessarily porous, which may open the door to the use of both CT directional drilling and hydraulic fracturing techniques, such as those employed for shale oil and gas extraction.

\section{$7 \quad$ Concluding remarks}

In the past 20 years, inflatable packer technology has developed to satisfy the needs of deep and high stress mining. Deeper, more remote and more accurate permeability testing is now readily included within an exploration coring program. There is potentially another revolution in mining techniques using hydraulic fracturing, as there has been in oil and gas, except this is likely as much for safety considerations addressing rockburst as it is for production purposes. 


\section{References}

Adams, J \& Roberts, R 2012, 'Advances in hydrogeological testing of mineral exploration boreholes', in CD McCullough, MA Lund \& L Wyse (eds), Proceedings of the International Mine Water Association Annual Conference, pp. 357-364.

ASTM International 2008, Standard Test Method for Determination of the In-Situ Stress in Rock Using the Hydraulic Fracturing Method, ASTM Standard D 4645, ASTM International, West Conshohocken, Pennsylvania.

Geodrilling International 2007, 'When you are in bear country why bother with nitrogen?', Geodrilling International, November 2007, pp. 28.

Geodrilling International 2015, 'The right direction', special report, Geodrilling International, October 2015, pp. 8.

Haimsona, BC \& Cornet, FH 2003, 'ISRM suggested methods for rock stress estimation-Part 3: hydraulic fracturing (HF) and/or hydraulic testing of pre-existing fractures (HTPF)', International Journal of Rock Mechanics \& Mining Sciences, vol. 40, pp. 1011-1020.

Giacomel, A. \& Rowe, C., 1992, 'Inflatable packer fundamentals', Proceedings of the International Drilling '92 Conference, October 1992, Perth.

Lugeon, M 1933, Barrage et Géologie, Dunod, Paris.

Makówka, J \& Drzewiecki, J 2011, 'Directed hydrofracturing as a method of rock burst mitigation, methane drainage and stress state determination in rock mass', in Proceedings of 34 ICSMRI Conference, New Delhi, pp. 300-312.

Pardo, C \& Rojas, E 2016, 'Selection of exploitation method based on the experience of hydraulic fracture techniques at the EI Teniente Mine', Proceedings of the 7th International Conference \& Exhibition on Mass Mining (MassMin 2016), The Australasian Institute of Mining and Metallurgy, Calrton South, Victoria, pp. 97-104.

Sengupta, S, Dhubburi, S, Subrahmanyam, R, Kumar, S \& Govinda, S 2013, 'Estimation of the impact of mining on stresses by actual measurements in pre and post mining stages by hydrofracture method-A case study in a copper mine', in AP Bunger, J McLennan \& R Jeffrey (eds), Effective and Sustainable Hydraulic Fracturing, Proceedings of the International Conference for Effective and Sustainable Hydraulic Fracturing (HF2013), INTECH, Rijeka.

Swanson, EE \& Titone, BC 2013, 'Packer testing program design and management', in A Brown, L Figueroa \& C Wolkersdorfer (eds), Reliable Mine Water Technology Conference 2013, International Mine Water Association, Sydney, Nova Scotia.

Sweeney, GT 1982, Fluid pressurization apparatus and technique, United States Patent No. 4,357992, Tigre Tierra, Inc., Puyallup, Washington.

van As, A \& Jeffrey RG 2000, 'Hydraulic fracturing as a cave inducement technique at Northparkes Mines', Proceedings of MassMin2000, The Australasian Institute of Mining and Metallurgy, Carlton South, Victoria, pp. 165-172. 